\title{
Innovative Design of Excavator Based on Reconfigurable Modular Strategy
}

\author{
Peng Guo-qing, LI Fu-xing, Chen Peng, Cheng Yong \\ Xuzhou institute of technology, Xuzhou Construction Vehicles Appearance and Function \\ Design Research Center, Xuzhou 221008, China \\ E-mail:Saintlyboy@163.com
}

Keywords: Product Design; Modular Concept; Engineering Equipment; Excavator; Product Family; Multifunctionality

\begin{abstract}
. since large engineering equipment cannot meet customers' personalized demands or respond fast to market changes, the method to conduct innovative design of engineering equipment based on modular strategy is proposed here. With the innovative design of excavator for example and by combining the product characteristics of excavator, the modular design study was carried out and the modular design process worked out to utilize modular design method for excavator. By combining different function modules, effects with various functions can be achieved, providing an entry point for the sustainable development design of engineering machinery.
\end{abstract}

\section{Introduction}

With the slowdown of world economy, the engineering machinery development also becomes sluggish, leading to increasingly intensifying competition among different engineering machinery manufacturers. The key to remain invincible amid fierce market competition is to strengthen product innovation and R\&D. However, for the traditional product development mode, changes to the part of product result in changes to the overall structure. Consequently, the product design cycle becomes complicated and time-consuming, with costs increasing and efficiency lowered, so the traditional product development mode has lost its market competitiveness. Therefore, modern design method must be adopted to improve the traditional product design and production process.

\section{Overview of Modular Design Theory}

\section{Introduction of Modularization.}

Modular design is a concept proposed by European and American countries in 1950s. It's widely applied in manufacturing industry, as it can effectively solve the contradiction between the product specification and design and manufacturing cycle cost. The so-called modular design is to put together certain elements of product and constitute a subsystem with a particular function. With the subsystem as the general module, it's then assembled with other product elements, so as to produce series products with many different functions. With the rapid development of economic globalization, the engineering machinery manufacturing industry characterized by small-lot and customized production mode faces severe challenges, such as diversified customer demands and increasingly shortening delivery cycle. Modular design can effectively solve problems like high cost and long delivery cycle in the customized production and has now become the trend and only road to the development of engineering machinery products [1].

\section{Function of Modular Design.}

Modular product design strategy is to cope with many changes by sticking to small changes and to produce more products with as few costs as possible, so as to meet with various personalized demands. It's a method where the enterprise develops various products with multifunctionality and doesn't need to develop each product. So, it just needs to work out various kinds of function modules elaborately and then assemble them in different ways to constitute different products. With this method, it can shorten the product development and manufacturing cycle, enrich product lines and improve product quality, so as to respond fast to market changes; besides, it can reduce or 
eliminate its adverse effect on the environment, and facilitate the product reuse, upgrading and maintenance as well as the disassembly and recycling of abandoned products.

\section{Product Modular Design Flow}

\section{Product Modular Process.}

Excavator has been a mature product on the market and well-received with a large number of customized designs. At this time, customers' demands are relatively clear. So the main method is to analyze the company's existing historical data, such as product order, design, procurement, manufacturing, assembly and service, so as to conduct modular product design, achieve product generalization, standardization and serialization design, lower future product design cost and shorten design cycle. To make modular product sustainable, the tendency for customers' demands needs to be taken into consideration. Therefore, in analyzing the existing customers' demand information and design data, the future changes need to be predicted and customers' demand information acquired needs to be as precise and comprehensive as possible. And the product modular design needs to be conducted based on all the above information. The modular design flow for excavator is: firstly, learn about the actual demands of excavators' function through market survey; then, turn these demands into relevant functions; afterwards, integrate all these different functions, divide them into relevant module systems and examine if these functions satisfy actual demands; if yes, continue to design the module in details; if not, reanalyze the functions, as shown in chart 1.

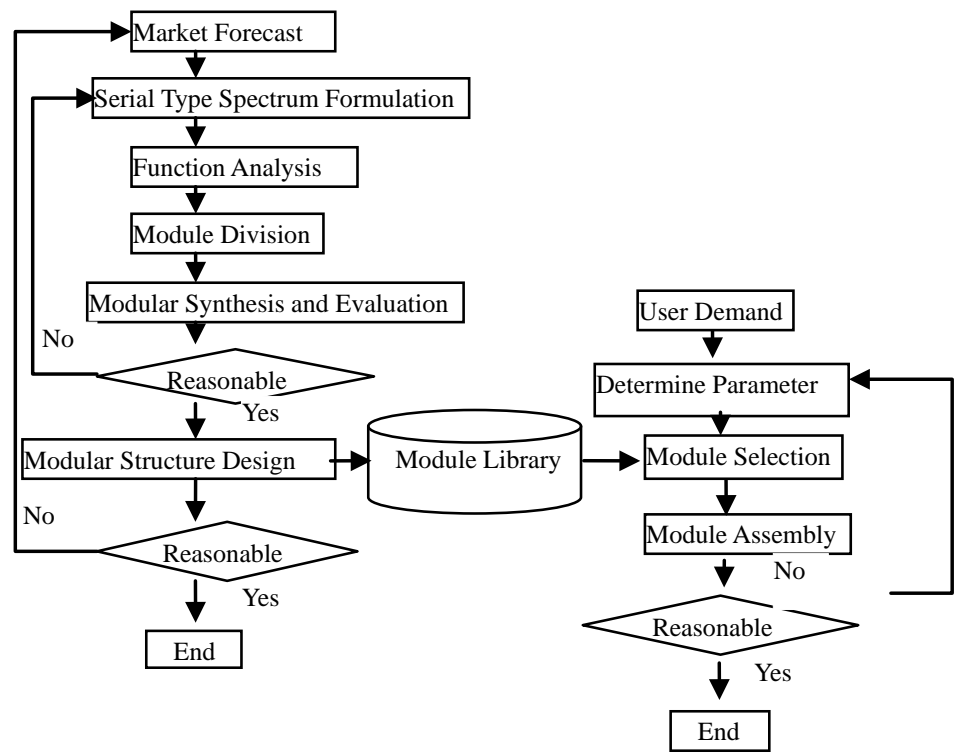

Chart 1 Modular Design Flow for Excavator

\section{Product Modular Strategy.}

Module is a constituting part of product that possesses an independent function. The product and module share the same geometric interface, and input and output interfaces. Modules of the same kind can be used repeatedly and exchanged, and relevant modules, if permutated and combined, can become the final product. Product modularization can generally adopt 7 basic strategies, namely, cross-product module sharing, basic type-based module exchange, individual module customization, module mixture, bus modularization, reconfigurable modularization and repeated assembly of same module, as shown in Chart 1. As for functions that can realize users' personalized demands, make them into optional modules and then satisfy different customers' demands through the selection and configuration of modules; as for parts that are of non-personalized or non-technical demands, make them into standard module, and reduce the product costs by using the standard module repeatedly among products [2]. 
Table 1 Basic Modular Strategy

\begin{tabular}{|c|c|c|c|}
\hline Strategy & Meaning & $\begin{array}{l}\text { Applicatio } \\
\text { n }\end{array}$ & Diagram \\
\hline $\begin{array}{l}\text { Cross-product } \\
\text { Module } \\
\text { Sharing }\end{array}$ & $\begin{array}{l}\text { Same module used for several products, } \\
\text { reducing the number of modules and } \\
\text { improving the universality of module. }\end{array}$ & $\begin{array}{l}\text { Standard } \\
\text { Fastener }\end{array}$ & \\
\hline $\begin{array}{l}\text { Individual } \\
\text { Module } \\
\text { Customization }\end{array}$ & $\begin{array}{l}\text { Components keep changing amid preset or } \\
\text { practical restrictions. }\end{array}$ & $\begin{array}{l}\text { Industrial } \\
\text { turbine and } \\
\text { furniture }\end{array}$ & \\
\hline $\begin{array}{l}\text { Module } \\
\text { Mixture }\end{array}$ & $\begin{array}{l}\text { Module mixed together form totally } \\
\text { different products. }\end{array}$ & $\begin{array}{l}\text { Products } \\
\text { designed } \\
\text { based on } \\
\text { parts library } \\
\end{array}$ & $\Delta \square$ \\
\hline $\begin{array}{l}\text { Bus } \\
\text { Modularization }\end{array}$ & $\begin{array}{l}\text { Apply standard structure that can attach } \\
\text { numerous different components and allow } \\
\text { the type, quantity and position of pluggable } \\
\text { modules to be variable }\end{array}$ & $\begin{array}{l}\text { Car } \\
\text { ( chassis is } \\
\text { the bus) and } \\
\text { computer }\end{array}$ & $\triangle \square$ \\
\hline $\begin{array}{l}\text { Reconfigurable } \\
\text { Modularization }\end{array}$ & $\begin{array}{l}\text { Allow any number of different components } \\
\text { to be configured in any ways, with standard } \\
\text { interfaces connecting the components }\end{array}$ & $\begin{array}{l}\text { Scaffold used } \\
\text { in } \\
\text { construction } \\
\text { field }\end{array}$ & 吕号 \\
\hline $\begin{array}{l}\text { Repeated } \\
\text { Assembly of } \\
\text { Same Module }\end{array}$ & $\begin{array}{l}\text { Satisfy personalized demands by increasing } \\
\text { or decreasing the number of same module }\end{array}$ & $\begin{array}{l}\text { Modular } \\
\text { hot-water } \\
\text { equipment }\end{array}$ & \\
\hline
\end{tabular}

\section{Module Interface Type.}

To facilitate the combination of different modules and fast swap of same modules, module interface will be required. As the characteristic set for connecting modules, module interface combines a series of peripheries of certain shape, size and precision with the surface to achieve the swap of substance, energy and information between module and other modules as well as the spatial orientation, so as to ensure the order of product structure and rapidity of module assembly. Therefore, interface design has become an important part of modular product design. The product modular interface type can be shown in Table 2.

Table 2 Product Module Interface Type

\begin{tabular}{|c|c|c|c|}
\hline $\begin{array}{l}\text { Classification } \\
\text { Method }\end{array}$ & Interface Type & Characteristics & Example \\
\hline \multirow{3}{*}{$\begin{array}{l}\text { Based on } \\
\text { the physical } \\
\text { characteristics of } \\
\text { interface }\end{array}$} & $\begin{array}{l}\text { Mechanical } \\
\text { Interface }\end{array}$ & $\begin{array}{c}\text { Propose requirements about the mechanical structure, } \\
\text { appearance, size, installation direction, installation } \\
\text { position, installation precision, etc; apart from meeting } \\
\text { with functional requirements, it should, like modules, be } \\
\text { swappable, compatible, reliable for installation, } \\
\text { convenient for disassembly and available for } \\
\text { maintenance, etc. }\end{array}$ & $\begin{array}{l}\text { Key, screw, bolt, pin and other interference fittings; } \\
\text { rivet, welding and other permanent connections; } \\
\text { gear, friction wheel, worm and other drive and } \\
\text { transmission devices need clip, buckle, injection and } \\
\text { other structures for high-efficient connection. }\end{array}$ \\
\hline & Pipeline Interface & $\begin{array}{l}\text { With relatively good air-tightness and convenience for } \\
\text { assembly and disassembly, etc. }\end{array}$ & Connection flange for pipe joint and pipe thread \\
\hline & Data Interface & $\begin{array}{c}\text { Data transmission, sharing and control among different } \\
\text { systems. }\end{array}$ & Fieldbus; data conversion interface procedure \\
\hline \multirow[t]{2}{*}{$\begin{array}{l}\text { Based on } \\
\text { modules' } \\
\text { relevance }\end{array}$} & Rigid Connection & $\begin{array}{l}\text { Direct assembly and connection; with dynamic and static } \\
\text { connections; }\end{array}$ & $\begin{array}{l}\text { Bolt connection (static) and gear connection } \\
\text { (dynamic) }\end{array}$ \\
\hline & $\begin{array}{r}\text { Flexible } \\
\text { Connection }\end{array}$ & $\begin{array}{l}\text { With connections for indirect and physical related } \\
\text { condition, but no connection for geometry-related } \\
\text { conditions }\end{array}$ & Sensor \\
\hline \multirow{2}{*}{$\begin{array}{l}\text { Based on the } \\
\text { position of } \\
\text { interface in } \\
\text { products }\end{array}$} & Internal Interface & $\begin{array}{l}\text { Connect and coordinate the parts inside products to } \\
\text { achieve the general target functions of products }\end{array}$ & $\begin{array}{l}\text { Interface between the rotor and air cylinder of } \\
\text { industrial turbine }\end{array}$ \\
\hline & External Interface & $\begin{array}{l}\text { Used for connecting products and external products, } \\
\text { impacting the performance of the more advanced } \\
\text { technical system for products }\end{array}$ & Flange plate for the output shaft of industrial turbine \\
\hline
\end{tabular}




\section{Modular Design Practice for Excavator}

\section{Clarify Tasks and Determine Demands. \\ (1) Introduction of Excavator}

As the main earthmoving machine, excavator has two functions, excavation and earth-moving, and it's mainly used for national construction project, mining project, real estate industry and such. The feedback on excavator's indoor work environment and its multifunctionality is: $80 \%$ friends hold that currently the excavators' functions have certain limitations-excavators' digging arm being not long enough. The indoor environment has certain limitations and the main problem is that the excavators' functions are too few. Each kind of excavator cannot be swapped for usage purposes. In complicated road conditions, excavator can exert little effect and it's not easy to clean the dirt on the digging bucket. Besides, people feel that the inside of excavator is the most severe part, as it has safety risks like over-temperature. Attention needs to be paid to this problem, as there will be building materials involved in the engineering projects. Furthermore, the health condition of excavators' operator needs to be taken care of, because if the working environment is poor, the operator will likely make mistakes, which will affect the engineering construction [3].

\section{(2) Excavators' Modular Demand}

In the operation process, the excavator's short digging arm cannot meet with job demand, so the excavator has to be moved constantly and if it's inconvenient for moving, then it will take much time to replace with another kind of excavator; the limited functions of excavator don't allow each kind of excavator to be swapped for usage purposes, such as forward and backhoe excavators, which will affect the construction progress in complicated situations; when the viewing angle of the front window or the operator's observation angle goes wrong, the operator needs to turn the angles and will easily get tired.

\section{Excavator's Modular Planning.}

(1) Excavators' Series Type Spectrum

Product module needs to be highly universal and if compared with non-module part, it is at an advantage, as it's produced in large quantity and can reduce costs and inputs. However, on the other hand, modules need to adapt to variable factors, such as the performance and form. Therefore, the requirement on the module flexibility is greatly raised. In terms of production, the category of module should be minimized, so as to achieve the objective of "one module for all multiple functions". From the perspective of product application, it tends to enrich the category of modules, so as to increase the variety. Concerning this contradiction, the design must start from the overall product system, analyze product function, performance, cost and other problems in a comprehensive manner, and determine the classification of modules reasonably. On a top-down basis, the product modular design can be classified as follows, system-level module, product-level module, component-level module and part-level module; according to the requirements on function, processing and assembly, it can be classified into basic module, universal module and dedicated module; then, according to its requirements on interface assembly, it can be classified into internal interface module and external interface module.

\section{(2) Excavators' Modular Planning}

Excavators' modularization is a kind of modular process targeted at existing products. According to the excavators' system configuration and functional theory, working device, driving gear, transmission gear, rotation supporting device, control system, etc. can be categorized as the main function modules of excavators, as shown in Chart 2; the driving cab, air circuit system, lubricating system, etc. can be categorized as the auxiliary function modules of excavators; the fire-fighting system, alarm system, lifting appliance, crane jib, etc can be categorized as the alternative function modules of excavators. 


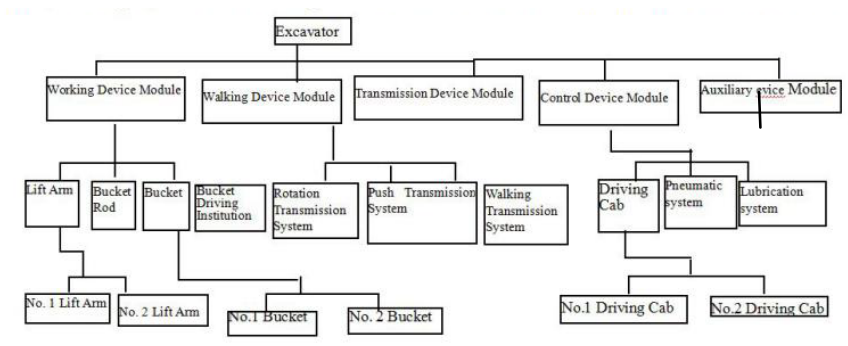

Chart 2 Diagram for Excavators’ Structure Module

\section{(3) Functional Decomposition of Excavator in Operation Process}

Excavator is mainly divided into the following parts, including driving cab, working device, walking device, transmission device, rotation support device, control system, etc. Wherein, the working device and driving cab are optional modules with multiple forms and need modular design, while other systems can be basic modules. Meanwhile, for different excavators, the production mode for their parts will also be different. The main operation process for excavators is shown in Chart 3. According to characteristics of excavator, for driving cab and bucket that can satisfy customers' personalized demands, make them into optional modules and meet with different customers' demands by the selection and configuration of modules; for parts that meet with non-personalized demands, such as gearbox and diesel engine, make them into standard modules and then share them in large numbers among products, so as to reach the objective of cost reduction[4].

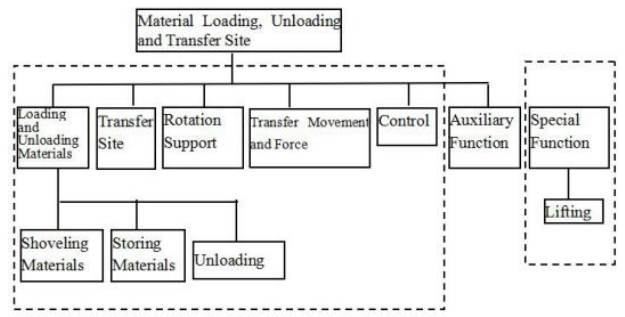

\section{Optional Module Design.}

Chart 3 Functional Decomposition Diagram for Excavator

\section{(1) Innovative Design for Bucket}

By making improvements to the modern multifunctional excavator, the excavator has got some new functions and can grab sand, wood, mow, etc. and the improvement to this excavator is that it combines its functions of grabbing cement bag and sand together. In the front of the excavator, it can grab a bundle of cement bags, saving labor forces; meanwhile, in the back, it can grab gravels, so it will be convenient and easy for workers to put the gravels into the bags on the construction site. Besides, the grab bucket can be exchanged with other different ones as per the job requirements, such as cement or wood, and it achieves the objective of one excavator for multiple functions, as shown in Chart 4.
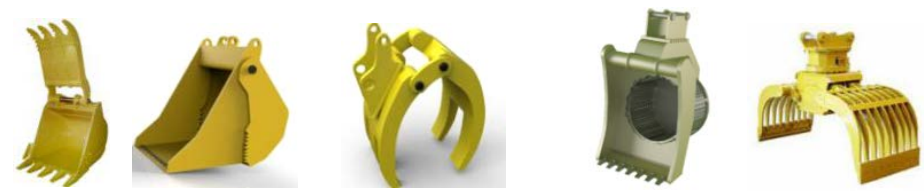

Chart 4 Different Design Schemes for Excavator

\section{(2)Innovative Design for Driving Cab}

The lines are not consistent with people's aesthetic requirements; however, the arc and curved surface can reflect features of natural beauty. The bend-forming arc frame structure of special pipe enables people to feel the smoothness, naturalness and beauty of lines. The arc of metal sheet parts is formed by calendaring, molding and welded with frameless double plating; the curved surface has streamline shape; both of them look delicate, smooth and natural, etc. So far, the driving cab of most engineering machineries in the world, such as excavator, has changed from the original straight line and edge styles to arc, curved surface streamline styles[5].

The arc-shaped modern driving cab has obstruction-free horizon, smooth lines and an air of fashion. The height and inclination angle of steeling wheel in the driving cab can be adjustable. The 
selection of a comfortable high-back damping seat prepares a good operating environment for drivers. The instrument and meter panel is designed properly and reasonably for easy observation and control.

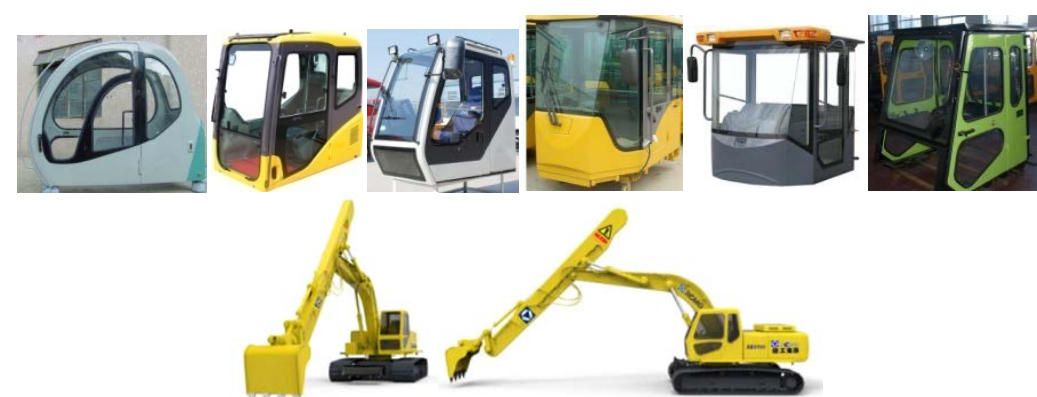

Chart 5 Different Design Schemes for Driving Cab

\section{Conclusion}

Modular product structure can be regarded as a revolution of design method and it's a brand-new and good way of thinking that solves complicated system problems and simplifies product structure. By introducing the modular design method into the innovative design of excavators and upgrading the traditional design mode for engineering machinery, the increasing demand for multiple varieties and specifications can be satisfied, which greatly reduces the repeated design work, improves the design efficiency, shortens product delivery cycle and creates benefits for enterprise development. With the in-depth development of modular design and along with the development of dedicated software, they will promote the R\&D of engineering machinery products.

\section{References}

[1] Hongyan Guan,Fengyu Yang,Qilei Wang. Study on evaluation index system of rubber materials for sealing, J. Materials and Design. 32(2011) 2404-2412.

[2] Poirson Emilie,Petiot Jean- Franois,Richard Florent. Amethod for perceptual evaluation of products by naive subjects: Application to car engine sounds, J.International Journal of industrial ergonomics. 40(2010) 504-516.

[3] Lin Chyunchau, Luh dingbang. A vision- oriented approach for innovative product design , J. Advanced Engineering Informatics, 23(2009) 191-200.

[4] HU Jie. Multimedia Creative Art[J].Beijing Journal of University of the Arts, 2008, 19 (4) : 78-81.

[5] LI Shi-guo, GU Zhen-yu. Interaction Design[M].Beijing:China Water Power Press,2012 . 